\title{
Congenital fistula between left ventricle and coronary sinus
}

\author{
KATHERINE M J MCGARRY, JAROSLAV STARK, FERGUS J MACARTNEY* \\ From the Thoracic Unit, The Hospital for Sick Children, Great Ormond Street, London
}

SUMMARY The occurrence of a congenital fistula between the left ventricle and the coronary sinus has not previously been reported. A patient with this rare anomaly is described in whom the diagnosis was established during life and confirmed at operation and necropsy.

A Caucasian female infant, weighing $2.8 \mathrm{~kg}$, was born by normal delivery after an uneventful pregnancy, at 38 weeks' gestation. Cyanosis was noted at birth and the child was followed up as an outpatient with an initial clinical diagnosis of tetralogy of Fallot. Her neonatal progress was unremarkable apart from slightly delayed milestones of motor development.

She was admitted to The Hospital for Sick Children, Great Ormond Street, at $2 \frac{1}{2}$ years of age, complaining of increasing dyspnoea on exertion. Examination disclosed a small child, on the third centile for height and weight. She was moderately cyanosed with clubbing of the digits, and was slightly tachypnoeic on exertion. Her heart rate was $100 / \mathrm{min}$ and regular. The jugular venous pulse was slightly raised with a pronounced a wave. There were no thrills palpable. The first heart sound was normal. A long ejection systolic murmur was audible at the left sternal edge, and the second sound was loud and single. Diastole was clear. The liver was not enlarged and physical examination was otherwise unremarkable.

\section{Investigations}

The haemoglobin concentration was $16 \mathrm{~g} / \mathrm{dl}$. The electrocardiogram showed evidence of biventricular hypertrophy with right atrial hypertrophy. The chest $x$-ray film showed situs solitus of the atria and viscera, and severe cardiomegaly, with a narrow vascular pedicle. Cardiac catheterisation and angiocardiography was carried out. It was noted during catheter manipulation that the coronary sinus was abnormally large. The haemodynamic data are recorded in the Table.

* Supported by the Vandervell and British Heart Foundations.
Angiocardiography in the frontal and lateral projections showed transposition with atrioventricular concordance, ventricular septal defect, and fibromuscular left ventricular outflow tract obstruction. The appearances also suggested the presence of a fistula between the left ventricle and the coronary sinus. In view of the lack of mixing at atrial level and the unequal atrial pressures, it was decided to proceed to Blalock-Hanlon atrial septectomy combined with a right Blalock-Taussig shunt.

Her postoperative course was satisfactory apart from an episode four months postoperatively when she developed supraventricular tachycardia with a ventricular rate of 300 beats/min, which responded to treatment with digoxin.

She was admitted for routine recatheterisation at the age of 5 years. The aortic saturation on this occasion was 81 per cent. Saturations of 21 and 46 per cent were recorded at different positions in the

Table Catheterisation data

\begin{tabular}{llll}
\hline Site & $\begin{array}{l}\text { Pressure } \\
(m m H g)\end{array}$ & $\begin{array}{l}\text { Mean pressure } \\
(m m H g)\end{array}$ & $\begin{array}{l}O_{2} \text { saturation } \\
(\%)\end{array}$ \\
\hline SVC & & & 50 \\
High RA & a 9 & 6 & 49 \\
Mid RA & v 5 & & 49 \\
Low RA & & & 49 \\
IVC & & & 49 \\
Coronary sinus & $100 / 8$ & & 56 \\
RV & $115 / 75$ & 95 & 59 \\
Aorta & a 8 & 4 & 58 \\
LA & v 9 & & 97 \\
L pul vein & $105 / 7$ & & 99 \\
LV & $15 / 8$ & 10 & 93 \\
PA & & & 80 \\
\hline
\end{tabular}

IVC, inferior vena cava; LA, left atrium; LV, left ventricle;

PA, pulmonary artery; $R A$, right atrium; $R V$, right ventricle;

SVC, superior vena cava. 
coronary sinus. Aortography showed a functioning Blalock-Taussig anastomosis. Selective left ventricular and coronary sinus angiocardiograms were exposed using standard fixed biplane cameras, but with the child lying in the long axis of the table with $45^{\circ}$ head-up tilt and the left shoulder tilted $30^{\circ}$ forwards. The films obtained with the lateral camera (Fig. 1) clearly showed a single narrow jet of contrast medium from the left ventricle into the coronary sinus, with no opacification of coronary arteries. In the films taken with the frontal camera, the orifice of the coronary sinus was seen to be greatly enlarged, yet only one-third the maximum diameter of the coronary sinus.

In August 1979 the child underwent complete repair on cardiopulmonary bypass because of increasing dyspnoea and cyanosis, using cardioplegic arrest with St. Thomas' solution ${ }^{1}$ for 125 minutes, the temperature of the heart being lowered to $12^{\circ} \mathrm{C}$. The preoperative diagnosis was confirmed. In particular, the coronary sinus was grossly dilated, measuring from outside $6 \times 4 \mathrm{~cm}$. The presence of the fistula (Fig. 2) was confirmed by opening the coronary sinus and exploring the left ventricle through the ventricular septal defect. The fistula was closed with two sutures of 4-0 Prolene buttressed with Teflon pledgets. Part of the wall of the coronary sinus was excised so as to. reduce the aneurysm, and the incision was then repaired. The Blalock-Taussig anastomosis was ligated, the atrial septal defect closed with a patch, and the standard Rastelli operation performed.

When the procedure was completed, the aortic clamp was removed and the patient completely rewarmed. The child was in sinus rhythm. At $37^{\circ} \mathrm{C}$, perfusion was gradually discontinued and intracardiac pressures measured. The pressure was $40 / 10 \mathrm{mmHg}$ in the right ventricle and $75 / 8 \mathrm{mmHg}$ in the left. The systemic pressure was $60 / 30 \mathrm{mmHg}$ and the mean pressures in the superior vena cava and left atrium were 20 and $15 \mathrm{mmHg}$, respectively. The blood pressure started to drop after about 20 minutes despite catecholamine support and the child died on the table.

At necropsy, the anatomical findings were confirmed, the repair appeared satisfactory, and there was no explanation for the fatal outcome. Postbypass histochemical studies from a left ventricular myocardial biopsy showed severe deterioration compared with the pre-bypass studies. This indicates poor myocardial protection during ischaemic arrest. Postmortem coronary angiography showed no interruption of any arteries.

The orifice of the coronary sinus just admitted a little finger. Immediately beyond the orifice was a large saccular aneurysm of the coronary sinus

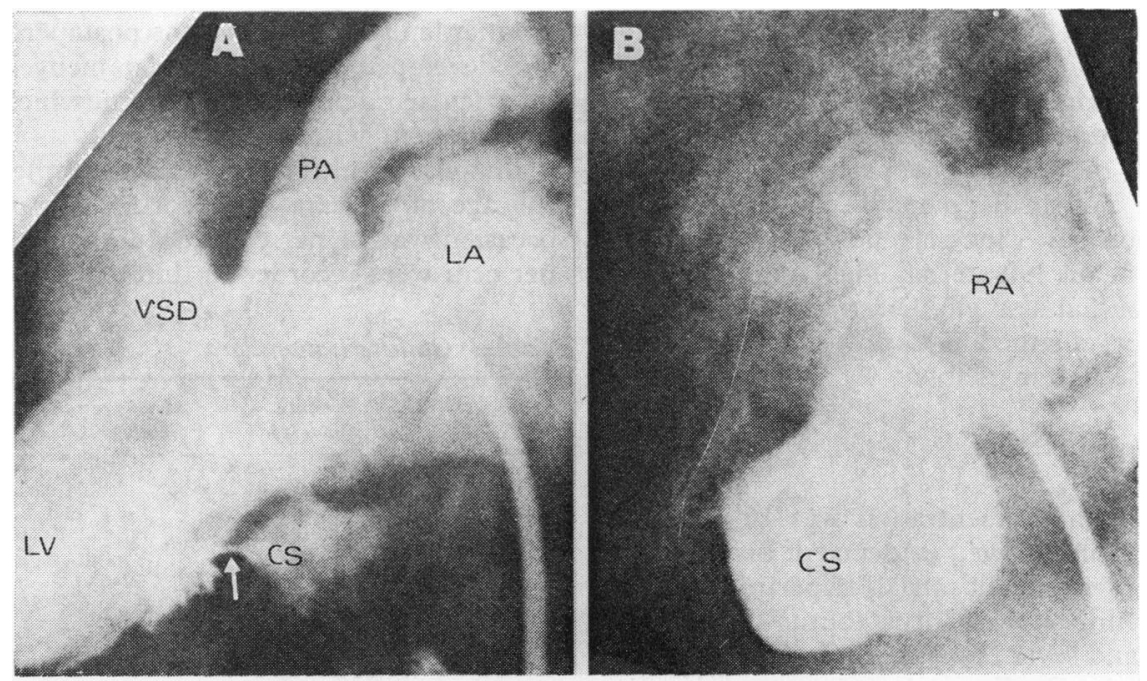

Fig. 1 (A) Left ventricular angiocardiogram in the modified right anterior oblique projection (see text) with craniocaudal tilt illustrating the fistula (white arrow) between the coronary sinus (CS) and the left ventricle (LV). There is catheter-induced regurgitation from the left ventricle to the left atrium $(L A)$. The right ventricle is.seen to fill through a single high ventricular septal defect (VSD). The left ventricular outflow tract is mildly constricted only in this projection, and the pulmonary valve is thickened. (B) Coronary sinus angiocardiogram in same projection as in (A) to show correspondence in position. The right atrium (RA) fills from the aneurysmal coronary sinus. 


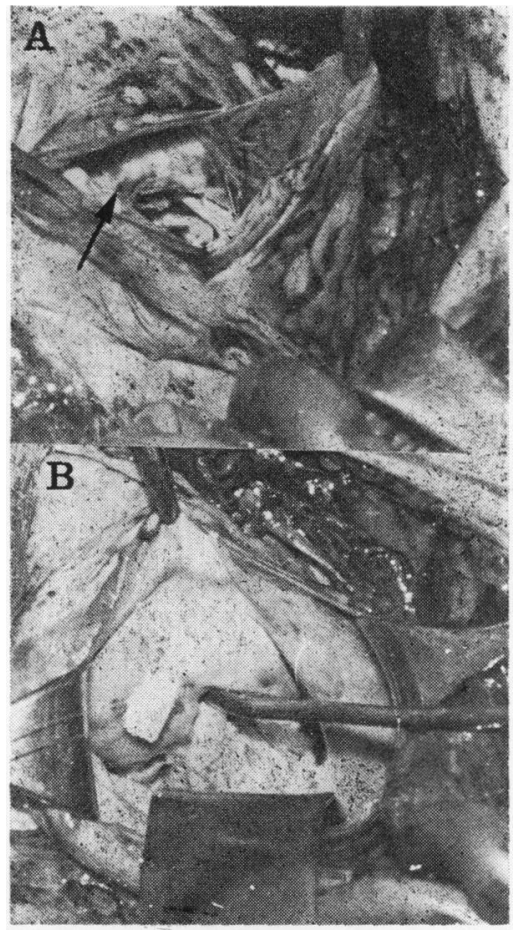

Fig. 2 (A) Operative photograph as viewed by the surgeon. The head is to the left and the feet to the right. The heart has been reflected cranially so as to expose the aneurysmal coronary sinus which has been opened with a longitudinal incision. An arrow marks the opening of the fistula. (B) Operative photograph; same general orientation as (A), but looking directly into the opened aneurysm of the coronary sinus. A probe lies in the fistula, and a pledget is being lowered along a suture to achieve closure.

measuring $6 \times 4 \times 2 \mathrm{~cm}$ passing toward the apex of the heart from the crux, this saccular aneurysm being a wide-mouthed diverticulum of the coronary sinus which, upstream to the aneurysm, was normal in course and structure.

From the interior of the left ventricle, the orifice of the fistula was not immediately visible. A prominent trabecula ran from the origin of the mural cusp of the mitral valve diagonally between the two papillary muscles. At the mitral annulus this was closely related to the posteromedial papillary muscle, but it ran diagonally toward the apex so as to lie adjacent to the origin of the anterolateral papillary muscle. On probing behind this tabecula, it was found to be free running, though $1 \mathrm{~cm}$ thick. On dividing the trabecular the orifice of the fistula was found as a $1 \mathrm{~mm}$ opening in a narrow endothelial lined sheet of fibrous tissue which held together the adjacent trabeculae of ventricular myocardium

\section{Discussion}

Congenital anomalies of the coronary sinus are frequently encountered during the surgical correction of complex congenital heart lesions, though the coronary sinus itself is seldom the site of an isolated anomaly. ${ }^{2}$ An excellent review of the subject by Mantini and colleagues ${ }^{3}$ includes a category of enlargement of the coronary sinus resulting from a high pressure left-to-right shunt into it, but this was always the result of a coronary artery-coronary sinus fistula. In one case with aortic atresia, myocardial sinusoids provided a route whereby left ventricular blood could reach the coronary sinus via the coronary arteries, but neither they nor, as far as we can determine, anyone else have described a direct congenital fistula between the two chambers. There are two reports of traumatic left ventricular to coronary sinus fistula, ${ }^{4}$ but this aetiology can be discounted in this patient as, in retrospect, the fistula was obvious on the angiocardiograms taken before her first operation. The diagnosis was not suspected before cardiac catheterisation, but the first clue was a capacious coronary sinus with an oxygen saturation in excess of that in the right atrium. Oblique angiocardiograms with craniocaudal tilt ${ }^{6}{ }^{7}$ provided particularly good visualisation of the fistula on injection into the left ventricle, and the fact that the fistula ran into the coronary sinus was confirmed by comparison of this angiocardiogram with that obtained by injection into the coronary sinus.

We were unable to explain the death at operation. The results of histochemical evaluation of left ventricular myocardial biopsy indicate poor myocardial protection during ischaemia. The mechanism of myocardial damage remains unclear, as we used our usual technique of myocardial protection which consists of infusion of cardioplegic solution into the root of the aorta, keeping the myocardial temperature between 10 and $20^{\circ} \mathrm{C}$, and ensuring that electrical activity does not resume while the aorta is clamped. We also have no explanation as to why the repair of the fistula should do any harm and in particular cause the myocardial damage found. The left ventricular wall structure was disturbed in the region of the fistula, but the angiocardiograms showed no hypokinesis, and there was no reason to suppose from the necropsy appearances that overall contraction in the region of the fistula was abnormal. This was only the second death after Rastelli's operation in a group of 20 children who have undergone the repair since January 1977. 


\section{References}

1 Jynge P, Hearse DJ, Braimbridge MV. Myocardial protection during ischemic cardiac arrest. A possible hazard with calcium-free cardioplegic infusates. $\mathcal{I}$ Thorac Cardiovasc Surg 1977; 73: 848-55.

2 Frank CG, Maloney JV Jr. Surgical significance of congenital anomalies of the coronary sinus. $f$ Cardiovasc Surg (Torino) 1968; 9: 420-7.

3 Mantini E, Grondin CM, Lillehei CW, Edwards JE. Congenital anomalies involving the coronary sinus. Circulation 1966; 33: 317-27.

4 Morritt GN, Jamieson MPG, Irving JB, Marquis RM, Walbaum PR. Development of left ventricularcoronary sinus fistula following replacement of mitral valve prosthesis. $\mathcal{F}$ Thorac Cardiovasc Surg 1978; 76 : 381-4.
5 Miller DC, Schapira JN, Stinson EB, Shumway NE Left ventricular-coronary sinus fistula following repeated mitral valve replacement. $f$ Thorac Cardiovasc Surg 1978; 76: 43-5.

6 Bargeron LM Jr, Elliott LP, Soto B, Bream PR, Curry GC. Axial cineangiography in congenital heart disease. Section I. Concept, technical and anatomic considerations. Circulation 1977; 56: 1075-83.

7 Rees PG, Daly K, Taylor JFN, Chrispin AJ, Macartney FJ. Craniocaudal tilt in angiocardiographic visualisation of congenital heart defects (abstract). $\mathrm{Br}$ Heart $\mathcal{f} 1978$; 40: 1065.

Requests for reprints to Professor F J Macartney, The Hospital for Sick Children, Great Ormond Street, London WC1N 3JH. 